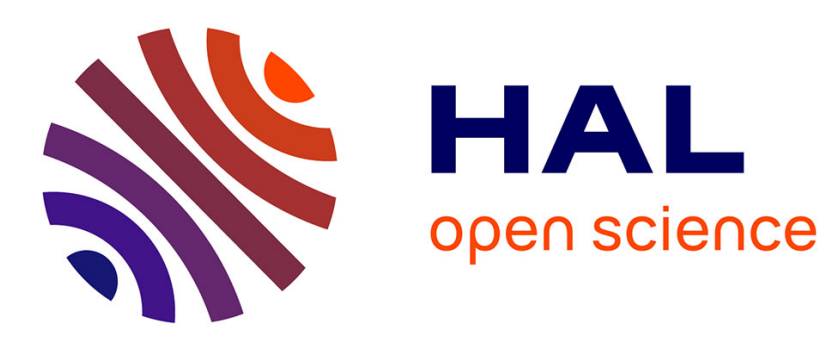

\title{
Regulation of GPCR signal networks via membrane trafficking
}

\author{
F. Jean-Alphonse, A.C. Hanyaloglu
}

\section{To cite this version:}

F. Jean-Alphonse, A.C. Hanyaloglu. Regulation of GPCR signal networks via membrane trafficking. Molecular and Cellular Endocrinology, 2010, 331 (2), pp.205. 10.1016/j.mce.2010.07.010 . hal00654486

\section{HAL Id: hal-00654486 \\ https://hal.science/hal-00654486}

Submitted on 22 Dec 2011

HAL is a multi-disciplinary open access archive for the deposit and dissemination of scientific research documents, whether they are published or not. The documents may come from teaching and research institutions in France or abroad, or from public or private research centers.
L'archive ouverte pluridisciplinaire HAL, est destinée au dépôt et à la diffusion de documents scientifiques de niveau recherche, publiés ou non, émanant des établissements d'enseignement et de recherche français ou étrangers, des laboratoires publics ou privés. 


\section{Accepted Manuscript}

Title: Regulation of GPCR signal networks via membrane trafficking

Authors: F. Jean-Alphonse, A.C. Hanyaloglu

PII: $\quad$ S0303-7207(10)00371-0

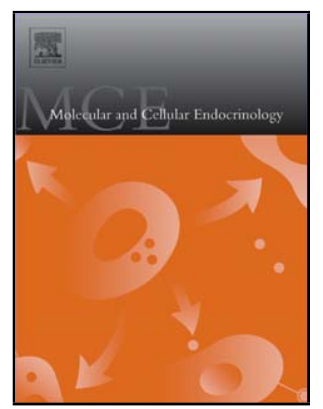

DOI: doi:10.1016/j.mce.2010.07.010

Reference: MCE 7597

To appear in: Molecular and Cellular Endocrinology

Received date: $15-12-2009$

Revised date: $7-6-2010$

Accepted date: 13-7-2010

Please cite this article as: Jean-Alphonse, F., Hanyaloglu, A.C., Regulation of GPCR signal networks via membrane trafficking, Molecular and Cellular Endocrinology (2010), doi:10.1016/j.mce.2010.07.010

This is a PDF file of an unedited manuscript that has been accepted for publication. As a service to our customers we are providing this early version of the manuscript. The manuscript will undergo copyediting, typesetting, and review of the resulting proof before it is published in its final form. Please note that during the production process errors may be discovered which could affect the content, and all legal disclaimers that apply to the journal pertain. 


\section{Regulation of GPCR signal networks via membrane trafficking}

F. Jean-Alphonse and A. C. Hanyaloglu ${ }^{1}$

Institute of Reproductive and Developmental Biology, Dept. Surgery and Cancer, Faculty of Medicine, Imperial College London

${ }^{1}$ Corresponding Author: Dr. Aylin Hanyaloglu,

Institute of Reproductive and Developmental Biology,

Hammersmith Campus, Du Cane Road

London, W12 0NN

UK

Email: a.hanyaloglu@imperial.ac.uk

Tel: +44 (0)20 75942128

Fax: +44 (0)20 75942184 
Keywords: GPCR; trafficking; signaling; endocytosis; recycling; degradation

\begin{abstract}
G protein-coupled receptors (GPCRs) are a superfamily of cell surface signaling proteins that act as central molecular activators and integrators in all endocrine systems. Membrane trafficking of GPCRs is a fundamental process in shaping extensive signaling networks activated by these receptors. Mounting evidence has identified an increasingly complex network of pathways and protein interactions that a GPCR can traverse and associate with, indicating a multi-level system of regulation. This review will discuss the recent developments in how GPCRs are trafficked to the cell surface as newly synthesized receptors, their recruitment to the clathrin-mediated pathway for endocytosis, and their sorting to subsequent divergent post-endocytic fates, focusing primarily on hormone-activated GPCRs. Current models depicting the classic roles membrane trafficking plays in GPCR signaling have evolved to a highly regulated and complex system than previously appreciated. These developments impart key mechanistic information on how spatial and temporal aspects of GPCR signaling may be integrated and could provide pathway-specific targets to be exploited for therapeutic intervention.
\end{abstract}




\section{INTRODUCTION}

Ligand-dependent activation of cellular signaling networks by the superfamily of $G$ protein-coupled receptors (GPCRs) involves both heterotrimeric G protein and G protein-independent signaling pathways. Given that a single ligand can generate multiple signaling responses, and that a single cell expresses multiple distinct cell surface receptors, raises the question of how this information is integrated or translated into specific cellular and physiological responses. Membrane trafficking is one key mechanism in defining these responses in complex signaling pathways. For many types of membrane cargo, including GPCRs, this represents a fundamental means not only to dictate sensitivity of a tissue to its ligand, but more recent findings illustrate that it is also vitally important in providing spatial control of a signal.

GPCRs remain at the forefront of many drug target programs due to their central role in all physiological systems and that perturbations in their activity can result in a multitude of diseases, including; obesity, diabetes, congestive heart failure, hormonedependent cancers and infertility, to name only a few. Disease-causing mutations in GPCRs can have dramatic impacts on cell signaling, but it is also becoming apparent that disruption of cell signaling could result from perturbations in the trafficking system (Polo and Di Fiore, 2006, Sorkin and von Zastrow, 2009). This review will give a brief overview of the trafficking pathways that GPCRs traverse, from cell surface targeting, to agonist-induced internalization and the divergent post-endocytic fates. Focus will primarily be on recent developments in each of these trafficking pathways, particularly for endocrine-relevant GPCRs.

\section{THE LIFE CYCLE OF GPCRS: A BRIEF OVERVIEW OF CURRENT PARADIGMS}

\section{a) Trafficking from ER/Golgi to plasma membrane}

Like many other membrane proteins, GPCRs are synthesized and processed in the endoplasmic reticulum (ER). Post-translational modifications such as glycosylation and ubiquitination, oligomerization with other receptor molecules, association with accessory chaperone proteins and folding take place in this compartment and are necessary for export (Achour et al., 2008, Tan et al., 2004). Subsequent trafficking through the ER and Golgi intermediate compartment (ERGIC) and Golgi apparatus also facilitates maturation and correct targeting to the cell surface. All three compartments are known to act as a strict quality control system for protein misfolding and accumulation (Conn and Janovick, 2009a, Ellgaard and Helenius, 2003). This quality control system includes ER-resident chaperones, such as calnexin, calreticulin and members of the protein disulfide-isomerase family (e.g. ERP-57) that sense membrane insertion and di-sulphide bond formation (Williams, 2006, Ellgaard and Helenius, 2003, Anelli and Sitia, 2008, Ayala Yanez and Conn, 2010). The quality control system also provides correct association with other chaperone proteins that regulate folding and/or transport through the ER/Golgi (Dong et al., 2007, Cooray et al., 2009). If protein folding fails, the defective GPCR is then targeted for degradation via the proteasome pathway. The identity of accessory proteins involved in the regulation of GPCR cell surface access are still rudimentary for the majority of GPCRs, although for some hormone-activated GPCRs like adrenocorticotropic hormone (ACTH) receptor, there are receptor-specific chaperone proteins that regulate its cell surface access (see accompanying Review by Clark et al., 2010). A lot of our understanding of these trafficking pathways has been facilitated by identification of disease-causing mutations in GPCRs that result of 
intracellular retention in the ER or Golgi compartments, such as X-linked nephrogenic diabetes insipidus, Familial hypocalciuric hypercalcemia, Familial glucocorticoid deficiency or hypogonadotropic hypogonadism (Conn et al., 2007).

\section{b) GPCR recruitment to clathrin-coated pits (CCPS) and internalization}

Once at the cell surface, GPCRs are able to bind its ligand, which initiates receptor activation of various signaling cascades. Cell surface signaling is well known to be regulated at a temporal level by membrane trafficking of GPCRs from the cell surface. This rapid ligand-induced internalization, contributes to acute signal termination or desensitization of G-protein signaling (Figure 1). The internalization of many GPCRs occurs primarily via clathrin-coated pits (CCPs) involving a mechanism whereby adaptor proteins of the arrestin family, $\beta$-arrestins 1 and 2 , play a central role (extensively Reviewed for e.g. (Moore et al., 2007, Reiter and Lefkowitz, 2006, DeWire et al., 2007)). In this model, $\beta$-arrestin is recruited from the cytoplasm to the activated and phosphorylated GPCR (by members of the GPCR kinase (GRKs) family), resulting in uncoupling the receptor from its cognate G-protein. $\beta$-arrestin also drives receptor clustering in to CCPs, via its ability to bind both GPCR and CCP proteins, namely the $\beta$-subunit of the adaptor protein AP2 and heavy chain of clathrin (Figure 1). Once GPCRs are concentrated in CCPs, the scission of vesicles from the plasma membrane involves the large GTPase dynamin, which is recruited to the $\mathrm{CCP}$, resulting in internalization of cargo to the endosomal compartment.

\section{c) From early endosome to divergent endocytic pathways}

Once internalized, GPCRs can traverse distinct trafficking routes that further shape the signaling response. GPCRs are either: rapidly targeted to the lysosome for its degradation resulting in complete termination of receptor signal activity, rapidly recycled back to the plasma membrane resulting in resensitization and hormone signal recovery, or are retained in endosomes, traversing the degradative and/or recycling pathways at a much slower rate (Figure 1) (Hanyaloglu and Zastrow, 2008, Marchese et al., 2008). A family of small GTPases, Rabs, play essential roles in trafficking, and can regulate and characterize compartments of these pathways (Seachrist and Ferguson, 2003). Following internalization to Rab5 positive early endosomes, receptors can recycle to the plasma membrane via Rab4 and/or Rab5/Rab4-positive vesicles (the "short cycle") or progress to Rab11-positive perinuclear recycling endosomes, from where they may either recycle to the plasma membrane via Rab11, (the "long cycle") or are sorted to MVB/lysosomal degradation pathways via Rab7-postive late endosomes (Figure 1). The sorting fate of GPCRs determines the heterotrimeric G-protein signaling pattern on a temporal level (resensitization versus long-term signal termination). Furthermore, GPCRs can activate non G-protein signaling pathways from endosomes, mainly via GPCR/ $\beta$ arrestin complexes, that create scaffolds for association with MAPK signaling molecules. This suggests an important spatial role, as well as temporal control, for GPCR membrane trafficking (Reiter and Lefkowitz, 2006).

How GPCRs are sorted in to these divergent pathways is not as well understood as mechanisms of receptor internalization, but what is certain is that these trafficking fates are highly regulated events, determined by sorting sequences encoded in the GPCR intracellular domains of the GPCR's. For example, entry of many GPCRs to the recycling pathway (e.g. $\beta 2$-adrenergic receptor, luteinizing hormone receptor, 
thyrotropin-stimulating hormone receptor) is highly dependent on specific cytoplasmic carboxy-tail (C-tail) sequences (Hanyaloglu and Zastrow, 2008, Marchese et al., 2008).

These next sections will highlight the recent studies that illustrate both the complexity of these trafficking pathways, and how membrane trafficking offers a means for tight spatio-temporal control of signaling from GPCRs in endocrine systems. Consequently they challenge the classical models that these pathways play in regulating GPCR signal activity.

\section{TRAFFICKING OF GPCRs FROM ER/GOLGI}

\section{Positive and negative regulation of membrane trafficking}

Trafficking of GPCRs through the biosynthetic pathway to the cell surface is a tightly regulated mechanism with multiple steps and a stringent quality control system to ensure correct GPCR folding and targeting. As stated above, association of GPCRs with accessory proteins or chaperones are a key step for the forward trafficking through the ER and Golgi. Some of these chaperones maybe quite receptor specific e.g. melanocortin receptor accessory proteins (MRAPs) (Webb and Clark, 2009), RACK1 (Parent et al., 2008) and M10 family of major histocompatibility proteins (MHC) (Loconto et al., 2003), while others are able to bind many GPCRs such as RAMPs (receptor activity modifying proteins) (Sexton et al., 2006) and GEC1 (glandular epithelial cell 1) (Chen et al., 2009). All of these accessory proteins play a role in driving the trafficking of the receptor to the surface. More recently, there have been molecules identified that negatively regulate this process. For example, the protein NECAB2 (Neuronal Ca2+-binding protein 2) interacts with the C-tail of the Adenosine $2_{\mathrm{A}}$ receptor in order to reduce plasma membrane expression of the receptor (Canela et al., 2007). Interestingly, recent findings have shown the MRAPs can have a dual role in regulating surface expression of specific subtypes of the melanocortin receptor family, negatively regulating MC4R and MCR5, but positively regulating MCR2, however, the mechanism behind this duality in the MRAPs is as yet unknown (Chan et al., 2009).

It is becoming apparent that many GPCRs form homo and/or hetero-dimers or higher order oligomers and that dimerization could both positively and negatively regulate GPCR cell surface targeting (see e.g. (Milligan, 2010, Gurevich and Gurevich, 2008) for recent reviews). Some of these receptors are hormone-activated GPCRs exhibiting constitutive dimers/oligomers, which form during biosynthesis e.g. the V1a and V2 vasopressin receptors, oxytocin receptor, $\beta 2$-adrenergic receptor and gonadotrophin hormone (LH/hCG and FSH) receptors (Terrillon et al., 2003, Guan et al., 2009, Guan et al., 2010). It is thought that dimerization is a necessary prerequisite for correct surface targeting for some GPCRs and there have been numerous reports of inactivating mutations in hormone-activated GPCRs that result in ER retention. Although none have been directly associated with unveiling a dimer interface, there are several reports where association of the mutant receptor with wildtype receptor results in inhibition of cell surface expression of the latter, e.g. calcium-sensing receptor and FSH receptor (Pidasheva et al., 2006, Zarinan et al., 2010), possibly explaining why heterozygous mutations can also result in disease. There have also been several reports that GPCRs can associate with splice variants of the same receptors, resulting in inhibition of both cell surface expression and 
signal activity. For example, there are four splice variants of the LH receptor reported to be expressed in the human ovary, primarily in luteinized granulosa cells and corpora lutea (Dickinson et al., 2009, Madhra et al., 2004, Nakamura et al., 2004). These $\mathrm{LH}$ receptor splice variants are able to associate with the immature form of the full length $\mathrm{LH}$ receptor, and even the FSH receptor, leading to ER retention (Minegishi et al., 2007, Yamashita et al., 2005). Expression of these variants is altered through the menstrual cycle, indicating that gonadotrophin signaling response could be temporally regulated in luteal cells by the timed expression of $\mathrm{LH}$ receptor splice variants (Dickinson et al., 2009). This also suggests that the level of surface receptor could be regulated in vivo by dimerisation, an avenue that is currently being explored therapeutically with small molecule pharmacological chaperones (see below) and expression of receptor fragments via gene therapy approaches (Conn and Janovick, 2009a, Zarinan et al., 2010).

\section{Are GPCRs active during the biosynthetic pathway?}

The initial site of activity for all GPCRs is via binding of an endogenous extracellular ligand at cell surface, given that most endogenous ligands are not cell permeable. This is the most conventional and accepted model for GPCR activation and G protein signaling (Figure 2). The requirement for plasma membrane expression is highlighted by GPCR mutations that impair cell surface trafficking and result in retention in the ER. Not surprisingly, many of these mutations lead to a loss of function and consequently can cause a variety of diseases depending on the receptor that is mutated (Conn et al., 2007). However, several strategies using synthetic cell permeable antagonists and agonists have been shown to assist receptor folding, restore cell surface expression and receptor function. For the V2 vasopressin receptor and mammalian $\mathrm{GnRH}$ receptors such compounds are being explored as therapeutic agents for nephrogenic-diabetes insipidus (NDI) and hypogonadotrophic hypogonadism respectively (Conn et al., 2007, Conn and Janovick, 2009b, JeanAlphonse et al., 2009, Robben and Deen, 2007). The use of cell permeable compounds, however, has also revealed an interesting and novel aspect to our understanding of GPCR activity. Recently, cell surface deficient NDI-mutants of the V2 vasopressin receptor have been shown to be intracellularly activated during its biosynthesis, by a new class of non-peptide plasma membrane permeable agonists (Robben et al., 2009). Treatment of V2 vasopressin receptor trafficking mutants by these agonists, but not the endogenous cell impermeable ligands, allowed Gas activation and cAMP accumulation. Such results could be a result of these compounds driving plasma membrane rescue of GPCR mutants, which then allows coupling of $G$ proteins at the cell surface, as shown with recent studies with other cell permeable agonists for the V2 vasopressin receptor (Jean-Alphonse et al., 2009). However, Robben et al, (Robben et al., 2009) showed no evidence for changes in maturation (via glycosylation levels) of these mutant receptors when treated with these permeable non-peptide agonists, arguing that the cAMP signals observed from the mutant receptors occurs intracellularly (Figure 2). This signaling activity was also reported to be sufficient in activating similar downstream cellular responses from the cell surface, as evidenced by translocation of aquaporin-2 to the apical membrane in polarized MDCK cells (Robben et al., 2009). Such a novel signal location may have implications for non-mutated GPCRs that are mostly observed to be intracellular, e.g., the human GnRH receptor or estrogen-responsive GPR30 (Finch et al., 2009, Revankar et al., 2005). Such an intracellular location could represent a reserve pool 
of receptors that can be readily trafficked to the cell surface when required, but these current studies may suggest an alternative signal requirement at its intracellular (potentially ER/Golgi) location. This may be more pertinent for GPCRs like GPR30 where their native ligand is a cell permeable hormone. Indeed, there are reports that GPR30 can activate calcium signaling from its ER location (Revankar et al., 2005), though the true functional cellular location for this GPCR is still debated (Filardo et al., 2007). However, studies with the $\beta 2$-adrenergic receptor have shown that during its trafficking through the ER/Golgi this GPCR is already pre-associated with its heterotrimeric $\mathrm{G}$ proteins and effector enzyme, adenylyl cyclase II, in a signaling complex (Dupre et al., 2007, Dupre and Hebert, 2006), supporting the idea that GPCR signaling can be activated in this compartment. It remains to be determined if other GPCRs can activate G-protein signaling from intracellular compartments, and if this signaling has a distinct cellular function to G-protein signaling from the cell surface.

\section{TRAFFICKING FROM THE CELL SURFACE TO THE ENDOSOME VIA CCPS}

\section{Fine-tuning of GPCR endocytosis via negative regulators of internalization}

Agonist-induced internalization for a lot of GPCRs involves a conserved and wellcharacterized $\beta$-arrestin-driven process (Figure 1). While it is evident that distinct GPCRs display receptor-specific behavior in how they utilize this pathway (see below), another concept, which has growing evidential support, is that endocytosis is exquisitely regulated by both positive and negative mechanisms. The current model depicts that $\beta$-arrestin binding to the GPCR commits the receptor to be driven into the series of events that culminate in receptor internalization. Yet, there are at least three points in this process where receptor targeting to the internalization pathway can be negatively regulated. Receptor internalization can be controlled at 1 ) the level of $\beta$ arrestin binding to a GPCR, either by regulation of $\beta$-arrestin recruitment to the membrane or at the level of receptor phosphorylation; 2) receptor recruitment in to CCPs; or 3) subsequent budding of a clathrin-coated vesicles. Recent data has provided evidence for regulation of GPCR internalization at each of these steps. One example of a protein that has been shown to be involved in regulating the first of these steps is the type $1 \mathrm{PDZ}$-domain-containing protein $\mathrm{Na}^{+} / \mathrm{H}^{+}$exchange regulatory factor 1 (NHERF-1), also called Ezrin-Radixin-Moesin (ERM)-binding phosphoprotein-50 (EBP50). NHERF-1 is a cytoplasmic scaffolding protein implicated in protein targeting and in the assembly of protein complexes (Weinman et al., 2006). NHERF-1 expression has been shown to prevent or displace $\beta$-arrestin association with the GPCR for parathyroid hormone (PTH)/PTH-related peptide, without affecting receptor phosphorylation. As elevated NHERF-1 levels inhibit dissociation of the receptor from its G-protein, this protein also prevents receptor signal desensitization (Wheeler et al., 2007, Wang et al., 2007, Wang et al., 2009). Although NHERF-1 is utilized for trafficking of other GPCRs, namely the $\beta 2$ adrenergic receptor and kappa-opioid receptor, the role of NHERF-1 in regulating GPCR internalization at the level of arrestin recruitment, so far, is specific for the PTH-receptors.

Agonist-induced internalization of GPCRs can also be specifically controlled at the level of GPCR/ $\beta$-arrestin recruitment in to CCPs. The Protein Linking IAP (CD47) to Cytoskeleton (PLIC-2, also called ubiquilin-2) was identified as the first negative regulator of this specific step in internalization. PLIC-2 is a member of a family of four 
homologous PLIC or ubiquilin proteins, each of which contains an N-terminal ubiquitin-like (UbL) domain that functions as a ligand for ubiquitin-interacting motifs (UIMs) present in proteins associated with the proteasome and endocytic adaptors (Walters et al., 2002, Regan-Klapisz et al., 2005). While PLIC proteins are known to function in targeting poly-ubiquitinated proteins to the proteasome, and more recently in autophagy-dependent cell survival (Kleijnen et al., 2000, Mah et al., 2000, N'Diaye et al., 2009), the localization of PLICs at the plasma membrane and with components of the cytoskeleton has suggested cellular roles in addition to regulating protein turnover (Wu et al., 1999). PLIC-2 (but not the related isoform PLIC-1) delays clustering, and thus internalization of the GPCRs V2 vasopressin receptor and $\beta 2$ adrenergic receptor, but not other membrane cargo e.g. EGF and transferrin receptors, into CCPs (N'Diaye $E$ et al., 2008). The molecular mechanisms may be via the ability of PLIC-2 to bind the CCP accessory protein Epsin, and thus inhibiting receptor entry in to the CCP (N'Diaye $\mathrm{E}$ et al., 2008). By modulating receptor clustering, PLIC-2 may have distinct roles in specifically regulating GPCR cell surface signal activity.

There are also mechanisms that regulate GPCR internalization at the level of the CCP. GPCRs with type 1 PDZ ligands, like the $\beta 2$-adrenergic receptor, exhibit a longer residency time in CCPs compared to receptors without PDZ ligands in their Ctails (Puthenveedu and von Zastrow, 2006). These GPCRs delay their internalization by modulating recruitment of dynamin. The observation that these receptors enter only into a subset of CCPs also suggest that spatial and temporal membrane organization of GPCRs may even function to tightly regulate its own rate of endocytosis, specify the downstream trafficking itinerary of receptors or even in formation of signaling microdomains (Mundell et al., 2006, Puthenveedu and von Zastrow, 2006). Although the PDZ ligand is associated with the ability of the $\beta 2$ adrenergic receptor to enter the recycling pathway from the endosome, it also suggests that, like NHERF-1 and the PTH receptor, GPCR-PDZ interactions with the actin cytoskeleton can regulate surface receptor levels via distinct mechanisms.

Overall, these findings highlight that distinct mechanisms both positively and negatively regulate each step of the internalization process, not only to fine-tune the kinetics of endocytosis but could also provide a platform for defining the nature of GPCR-protein complexes that regulate a myriad of distinct signaling pathways.

\section{New insights in to the core mediators of GPCR internalization: $\beta$-arrestins and GRKs}

With advancing technologies and imaging approaches, the classic GRK/ $\beta$-arrestin model of rapid GPCR desensitization and internalization is viewed as a pathway that is not as well understood as previously thought. There is diversity in the role of these endocytic proteins beyond regulation of GPCR activity, e.g. GRK's are involved in NFkB signaling (Patial et al., 2009) and more recently $\beta$-arrestin 2 has been shown to act as a co-repressor for nuclear androgen receptor (Lakshmikanthan et al., 2009). In turn, there is also great diversity in how GPCRs differentially utilize this system, which is critical in understanding the impact of these pathways for specific receptor systems in vivo. Furthermore, novel players or, novel regulatory features to these core-mediators of membrane trafficking continue to be uncovered.

Although GRK phosphorylation of activated GPCRs induces rapid desensitization via $\beta$-arrestin recruitment, there are several studies indicating that these common 
desensitization mechanisms can play other roles in spatio-temporal GPCR signaling. For example, phosphorylation of protease-activated receptor-2 (PAR-2) is not required for $\beta$-arrestin recruitment and internalization, but a PAR-2 mutant without phosphorylation sites on its $\mathrm{C}$-tail is unable to promote $\beta$-arrestin-dependent MAPK activation (Ricks and Trejo, 2009). $\beta$-Arrestin may also display differential sensitivity to certain hetero-trimeric $G$ proteins. $\mathrm{G} 15$, a member of the $\mathrm{Gq} / 11$ family that activates phospholipase $C$ is the first G-protein to be identified that is insensitive to $\beta$ arrestin-mediated desensitization (Innamorati et al., 2009). Due to the specific expression of G15 in hematopoietic precursor cells and activated lymphocytes, the authors suggest a physiological requirement for these cell types to maintain cell surface G15-protein signaling from diverse GPCRs (as G15 displays promiscuity in the receptors that it couples to). In turn this $\beta$-arrestin-resistant $G$ protein perhaps has implications in pathophysiological signaling occurring in diseases such as cancer (Innamorati et al., 2009).

In addition to phosphorylation and ubiquitination, recent data also suggests a role for S-nitrosylation in regulating core mediators of GPCR trafficking. $\beta$-arrestin, GRK2 and dynamin have all been demonstrated to be S-nitrosylated by endothelial nitric oxide synthase (eNOS) to modify their activity (Ozawa et al., 2008, Whalen et al., 2007, Wang et al., 2006). eNOS has been shown to bind and selectively S-nitrosylates $\beta$ arrestin 2, but not $\beta$-arrestin 1, on a single cysteine residue (Ozawa et al., 2008). Agonist activation of the $\beta 2$-adrenergic receptor causes eNOS dissociation from $\beta$ arrestin and promotes $\beta 2$-adrenergic receptor internalization by facilitating $\beta$-arrestin association with both AP-2 and clathrin (Ozawa et al 2008). S-nitrosylation of dynamin increases self-assembly, relocation to the plasma membrane and its GTPase activity (Wang et al., 2006, Kang-Decker et al., 2007). However, unlike $\beta$ arrestin and dynamin, S-nitrosylation of GRK-2 inhibits its kinase activity, negatively regulating $\beta 2$-adrenergic receptor phosphorylation, and consequently $\beta$-arrestindependent G-protein desensitization (Whalen et al., 2007). Although these findings may appear to be disparate, they support the idea discussed above in that these pathways are highly dynamic and controlled by both positive and negative mechanisms.

\section{Contrasting roles of GPCR-mediated internalization in regulating G-protein signaling}

In the classical model described so far, GPCR agonist stimulation triggers signaling of G-protein signaling at the plasma membrane that is acutely regulated at the temporal level by $\beta$-arrestin-mediated internalization. However, there have been several recent studies challenging the established connectivity between G-protein signal desensitization and GPCR internalization. Although prior studies have shown evidence of endosomal localization or even internalization of $\mathrm{G} \alpha$ subunits (Allen et al., 2005, Slessareva et al., 2006), two very recent elegant studies, however, clearly show a requirement for GPCR/G-protein internalization for sustained or persistent Gas signaling from an endosomal compartment (Calebiro et al., 2009, Ferrandon et al., 2009). Both studies employed the use of recently developed fluorescent resonance energy transfer (FRET) tools that allow measurement of cAMP production in real-time. CAMP is a well-characterized second messenger that activates several intracellular targets such as Epac (Exchange Protein Activated by cAMP), a cAMP binding protein resulting in activation of the small $G$ protein Rap1. An Epac-1CFP/YFP FRET construct based on a single cAMP-binding domain of Epac has been 
used as a cAMP sensor in living cells (Nikolaev et al., 2004), to study real time in vivo signaling dynamics of the parathyroid hormone receptor (PTHR) and thyroidstimulating hormone receptor (TSHR). Both studies show a requirement for GPCR internalization in sustained or persistent $\mathrm{G} \alpha \mathrm{s}$ signaling from an endosomal compartment.

In the case of the PTHR, the stability of the receptor-hormone complex is involved. The PTHR responds to two native ligands; the endocrine hormone PTH and paracrine acting PTH-related protein (PTHrP). By using FRET to measure both real time conformational changes within receptor and G-protein, and cAMP dynamics, the authors show that treatment with PTH, but not PTHrP, exhibited a prolonged GPCR activation and G-protein signal response (Ferrandon et al., 2009). PTH also stimulated co-trafficking of PTHR with Gas in to early endosomes, while PTHrP results in dissociation of Gas from its receptor prior to PTHR internalization. The differential response to its hormones is due to stable association of the PTH-receptor complex in a prolonged active conformation. Interestingly, internalization is required for this sustained signaling, as inhibition of internalization with a dynamin dominant negative mutant prevents this sustained CAMP production and results in desensitization (Ferrandon et al., 2009). This suggests that internalization of the receptor into the endosomal compartment may protect the receptor from $\beta$-arrestinmediated desensitization. Interestingly, PTH treatment of osteoblasts from $\beta$-arrestin 2 knockout mice promotes sustained cAMP signaling (Ferrari et al., 2005), supporting this idea. Whether $\beta$-arrestin 1 is involved in the internalization of the PTHR/G protein complex remains to be determined. This study does suggest that PTH induces a distinct receptor/protein complex required for co-trafficking of active GPCR/G-protein than that induced by PTHrP, perhaps due to association with proteins like NHERF-1 that prevent PTHR desensitization (see above section). The spatio-temporal differences in cAMP signaling from the PTHR in response to each of its hormones has been proposed to explain the opposing physiological actions of both hormones on bone remodeling (Ferrandon et al., 2009).

For the TSHR, TSH treatment also induces rapid internalization of the TSHR and colocalization with its cognate $\mathrm{G}$ protein, $\mathrm{G} \alpha \mathrm{s}$, and adenylate cyclase III (Calebiro et al., 2009). Furthermore, no desensitization of TSH-induced cAMP signaling was observed. Such a pattern of prolonged CAMP stimulation occurred under prolonged, but not short TSH stimulation, suggesting that receptor internalization prevents TSH dissociation from its receptor. By creating a transgenic mouse expressing an EpacFRET construct, the authors were able to study this phenomenon in thyroid follicles from these animals in culture. They show that the sustained endosomal cAMP production seems necessary for activation of downstream targets such as phosphorylation of the PKA-substrate vasodilator-stimulated phosphoprotein (VASP) and actin remodeling (Calebiro et al., 2009). Like the PTHR, the TSHR is also dependent on $\beta$-arrestin for its internalization (Frenzel et al., 2006), yet it is not certain how these more classical mediators of desensitization/internalization would be integrated into these new findings. Interestingly, a recently identified TSHRinteracting partner, the protein downstream regulatory element antagonist modulator (DREAM), has been shown to promote receptor coupling to Gos (Rivas et al., 2009). Overall, both of these studies show that GPCR-G protein signaling can occur from very distinct compartments and highlights the role that trafficking plays in providing a 
system for localized, spatially controlled signaling responses that may have very distinct cellular roles (Figure 2).

\section{POST-ENDOCYTIC TRAFFICKING FATE OF GPCRS}

\section{Ubiquitin mediates lysosomal sorting of GPCRs at multiple steps}

The physiological requirement for rapid sorting of activated GPCRs to lysosomes in permanent signal termination is illustrated in diseases where such pathways are impaired, e.g. the sustained signal activity due to inhibition of chemokine receptor CXCR4 and PAR1 degradation in invasive breast cancer (Marchese et al., 2008). Thus mechanistic knowledge is key in this biologically and clinically relevant pathway. A role for receptor ubiquitination has been determined for certain GPCRs in directing receptors to lysosomes. Furthermore, GPCRs, like other types of membrane cargo, can engage with endosomal sorting proteins namely HGF regulated tyrosine kinase substrate (Hrs) and components of the Endosomal Sorting Complexes Required for Transport (ESCRT) machinery for lysosomal sorting (see Reviews (Shenoy, 2007, Hanyaloglu and Zastrow, 2008, Marchese et al., 2008)). Hrs and the three ESCRT protein complexes (ESCRT I, II, \& III) act sequentially in the sorting of mono-ubiquitinated cargo at the endosomal surface prior to invagination and lumenal vesicle formation in the MVB (Raiborg and Stenmark, 2009). What has emerged recently is that the timing and/or pattern of ubiquitination are key in determining the sorting fate of a receptor.

Although several GPCRs have been shown to be ubiquitin modified (Shenoy, 2007, Marchese et al., 2008), the identities of the ubiquitin machinery involved, such as the E3 ligases, have only been identified for a few GPCRs. The E3 ligases that are known to ubiquitinate GPCRs include Nedd4 ( $\beta 2$-adrenergic receptor) (Shenoy et al., 2008), c-Cbl (PAR-2) (Jacob et al., 2005) and AIP4 (CXCR4) (Marchese et al., 2003). Although ubiquitination of these GPCRs is required for their sorting to lysosomes, without influencing agonist-induced internalization, ubiquitination of $\beta 2$-adrenergic receptor or CXCR4 does not occur if internalization is inhibited. For the $\beta 2$-adrenergic receptor, the mechanism involves $\beta$-arrestin recruitment of the Nedd4 ligase to the receptor (Shenoy et al., 2008). In contrast, $\beta$-arrestin is not involved in CXCR4 ubiquitination even though $\beta$-arrestin1 binds AIP4 and loss of $\beta$-arrestin1 inhibits receptor degradation (Bhandari et al., 2007).

Another component of the ubiquitination machinery that plays an important role in targeting GPCRs to the lysosome are the deubiquitnating enzymes (DUBs). Their action suggests that deubiquitination of receptor is also required for correct lysosomal sorting. For example, the PAR-2 receptor requires the DUBs, AMSH and UBPY for receptor deubiquitination in endosomes and an efficient routing to lysosomes (Hasdemir et al., 2009). These findings are consistent with prior observations with the calcium-sensing receptor, which requires binding to AMSH for its degradation (Reyes-lbarra et al., 2007).

Ubiquitination of other protein targets also plays a role in GPCR lysosomal sorting. The ubiquitination pattern of $\beta$-arrestin can dictate the post-endocytic sorting fate by contributing to the stable (GPCR endosomal retention) or transient (GPCR recycling) association of GPCRs with $\beta$-arrestin (Shenoy et al., 2007). However degradation of 
the $\mathrm{M} 1$ and $\mathrm{M} 2$ muscarinic receptor requires stable ubiquitination of $\beta$-arrestin, regardless of differences observed in stable association of $\beta$-arrestin with each receptor (Mosser et al., 2008). For the delta-opioid receptor, ubiquitination of the receptor is not required for its rapid degradation (Tanowitz and Von Zastrow, 2002, Hislop et al., 2004) but plays a distinct and novel role at a late step in lysosomal sorting (Hislop et al., 2009). Expression of a catalytically inactive mutant of E3 ubiquitin ligase AIP4 was found to inhibit receptor degradation when measured by binding of radiolabeled ligand, but not when assessed by biochemical approaches. This suggests ubiquitin plays a role after the receptor has sorted to lysosomes during proteolytic processing of the receptor. Deubiquitination by the DUBs AMSH and UBPY was also required for this process, highlighting that the cycling between ubiquitination and deubiquitination is a common regulatory feature in the ubiquitin system (Hislop et al., 2009). These observations could be relevant for other GPCRs and even for prior studies assessing the role of GPCR ubiquitination by ligandbinding approaches.

\section{New insights into targeted sorting of GPCRs to the recycling pathway}

It is well established that sorting of GPCRs to the recycling pathway is necessary for functional recovery, or resensitization, of G-protein signaling, under conditions of continued or repeated hormonal stimulation. However, chronic GPCR stimulation leads to rerouting of GPCRs from the recycling to the degradative pathway as part of the mechanism of receptor downregulation. Such reprogramming of the trafficking fate has significant therapeutic implications as it contributes to the phenomenon of tachyphylaxis, or drug tolerance (von Zastrow et al., 2003). Studies over the past few years has unveiled increasing complexity in how receptors are targeted to the recycling pathway, suggesting that this pathway may provide further cellular requirements than G-protein signal resensitization.

As mentioned above (and also recently reviewed in (Hanyaloglu and Zastrow, 2008, Marchese et al., 2008)) GPCR recycling is a targeted process occurring via a 'sequence-directed' mechanism. Yet for most receptors, little is known about the identity of the recycling proteins that bind to this sequence. With the exception of certain recycling sequences that conform to type 1 PDZ ligands in GPCR C-tails, recycling sequences are quite diverse, which suggests a high amount of receptor specificity in the proteins that they bind. However, there is also evidence that core endocytic machinery could regulate this trafficking mechanism. The early endosomelocalized adaptor protein Hrs has been identified as such a protein for the recycling of the GPCRs the $\beta 2$-adrenergic receptor, mu-opioid receptor and calcitonin-receptorlike receptor (Hanyaloglu et al., 2005, Hasdemir et al., 2007). Hrs is essential for recycling of these receptors, as knockdown of $\mathrm{Hrs}$ results in early endosomal retention. More recently Hrs has been shown to be required for the recycling of a tyrosine kinase receptor, the TrkA receptor (Huang et al., 2009), indicating that perhaps a sequence-directed mechanism of recycling is important for other kinds of signaling receptors. Of note, Hrs-dependent recycling for all these receptors is mediated via the N-terminal VHS domain of Hrs, a domain only characterized by its conserved presence in yeast $\mathrm{Hrs}$ (ㅁps27), $\underline{\mathrm{H}} \mathrm{rs}$, and the Hrs-interacting partner STAM (Hanyaloglu et al., 2005, Hasdemir et al., 2007, Huang et al., 2009). As Hrs is considered to be a scaffolding protein at the early endosome membrane and may not directly bind to the receptor cargo (Hanyaloglu et al., 2005), this suggests that, as 
yet, an unknown protein interacting with the Hrs VHS domain might be involved in targeting GPCRs to the Hrs-recycling mechanism.

There is also evidence supporting indirect and direct roles of $\beta$-arrestin in regulating sorting of GPCRs to the recycling pathway. For some GPCRs, slow recycling to the plasma membrane is attributed to the association-dissociation kinetics with $\beta$-arrestin, where transient associations facilitate rapid sorting, while strong association (mediated by GPCR phosphorylation and $\beta$-arrestin ubiquitination) leads to trafficking to the perinuclear compartment and slow recycling kinetics (Shenoy et al., 2007). For the $\mathrm{N}$-formyl peptide receptor, internalization is $\beta$-arrestin-independent, but receptor recycling is highly dependent on $\beta$-arrestin (Vines et al., 2003). This distinct role of $\beta$ arrestin in the recycling of this GPCR also implicates a novel role for the $\beta$-arrestinbinding protein AP-2 in regulating this process (Wagener et al., 2009). The importance of this pathway for receptor signaling are underscored by the findings that disruption of $\beta$-arrestin-mediated recycling causes accumulation of receptor/ $\beta$ arrestin complexes in the late recycling compartment and aberrant signaling that leads to apoptosis (Vines et al., 2003, Wagener et al., 2009).

A recurring theme in understanding membrane trafficking is that the pattern or timing of activity, defined by protein-protein interactions or post-translational modifications, are important determinants of receptor fate. Thus, the pattern of receptor phosphorylation can determine the sorting fate. For the mu-opioid receptor, the receptor phosphorylation state determines the trafficking to distinct recycling pathways. Thus, phosphorylated receptors enter the fast, Rab4-mediated recycling pathway, whereas non-phosphorylated receptors recycle via the 'Iong cycle' or Rab11 pathway (Wang et al., 2008). By altering the pattern of receptor phosphorylation, a cell can alter its recycling kinetics, which in turn provides a mechanism to alter the kinetics of resensitization and tissue responsiveness. The identity of the kinases involved in GPCR phosphorylation and post-endocytic sorting includes the GRKs. The D2 dopamine receptor has recently been shown to require GRK2 and GRK3 phosphorylation, not for rapid desensitization or $\beta$-arrestin binding, but as an important determinant of receptor recycling (Namkung et al., 2009). This agrees with prior data with the $\beta 2$-adrenergic receptor, where a GRK5 phosphorylated serine in the receptor C-tail recycling sequence (DSLL) is necessary for receptor targeting to this pathway (Cao et al., 1999). However, more recently, the cAMP-dependent kinase, PKA, has been shown to be involved in unprecedented features of regulated recycling for the $\beta 2$-adrenergic receptor (Yudowski et al., 2009). Employing imaging techniques such as total-internal reflection (TIRF) microscopy, that allow imaging of membrane events with high axial and temporal resolution, have obtained novel insights into receptor trafficking. With this technique, GPCR recycling (measured by membrane insertion events) was observed to be very rapid, occurring within 3-5 minutes of agonist stimulation (Yudowski et al., 2009). Furthermore, in neurons, the $\beta 2$-adrenergic receptor insertion events differed in their time to laterally diffuse in the membrane, termed as transient or persistent events (Yudowski et al., 2006). As the $\beta 2$-adrenergic receptor is a Gos coupled receptor that activates PKA, the authors identified that chemical inhibition of PKA increases the frequency of transiently localized recycling events (Yudowski et al., 2006). The site of PKA action is at a PKA consensus site in the receptor $\mathrm{C}$-tail, distinct from the distal recycling sequence, as mutation of the PKA site also increased frequency of recycling events. These findings again illustrate the acute fine-tuning capacity of these pathways and 
also allude to a signal compartmentalization role for persistent receptor insertion events (Yudowski et al., 2006, Yudowski et al., 2009). These may represent membrane scaffolding proteins that the $\beta 2$-adrenergic receptor is known to form complexes with, such as the A kinase anchoring proteins (AKAPs). AKAP5 and AKAP12 not only provide a platform for compartmentalizing signaling molecules such as PKA and c-Src with $\beta 2$-adrenergic receptor, but are also involved in regulating recycling and resensitization, and even recently, signaling to the MAP kinase pathway (Tao and Malbon, 2008, Tao et al., 2007, Tao et al., 2003).

\section{CONCLUSIONS \& PERSPECTIVES}

It is becoming apparent that membrane trafficking is a highly complex system, comprising multiple steps, with mechanisms for both positive and negative regulation at each of these steps. Figure 3 illustrates only a fraction of the complexity of the pathways and molecules that a GPCR can traverse and associate with. Yet it is such complexity that provides a platform for exquisite control of receptor signaling events. GPCR trafficking can potentially be 'reprogrammed' to a number of alternate fates to achieve very distinct signaling patterns, a feature that in endocrine systems could be highly advantageous for cells exposed to dynamic hormonal environments (Hanyaloglu and Zastrow, 2008). In addition, membrane trafficking provides potential for activation of multiple GPCR signaling sites, for both G-protein signaling and non G-protein signaling pathways (Figures $2 \& 3$ ), in addition to its well-known roles in desensitization and resensitization.

The majority of research focuses on activation and trafficking of a single receptor, yet as stated in the Introduction, a single cell would control activity of multiple receptors, including GPCRs that can form both homo and hetero-dimers. Therefore, the next challenge is translating the possible permutations of trafficking fates and signaling outputs to biological end-points in specific physiological systems. Systems biology approaches are being applied to GPCR signal networks (Heitzler et al., 2009, Linderman, 2009) and membrane trafficking would be an important component in these approaches, as it is becoming accepted that signaling and trafficking are essentially one system (Sorkin and von Zastrow, 2009). These complex trafficking systems also provide avenues for development of pathway specific compounds, such as the recent interest in ligands that could have high specificity to particular signaling or trafficking pathways (also termed biased-agonists, or ligand-directed signaling) and thus have minimal side effects (Violin and Lefkowitz, 2007, Kenakin, 2007). For example, a number of compounds that specifically activate $\beta$-arrestin signaling, but not G-protein coupling, have been reported (Violin and Lefkowitz, 2007, Drake et al., 2008, Shukla et al., 2008, Azzi et al., 2003). There are also reports of compounds that can induce differential GPCR sorting, rerouting receptors from the recycling pathway utilized by the native ligand and inducing receptor ubiquitination and downregulation (Gonzalez-Cabrera et al., 2007, Oo et al., 2007). This highlights the potential value of GPCR trafficking assays as tools in drug discovery programs. Overall, as we begin to understand more of how these pathways impact downstream cellular programs, this will in turn open up numerous possibilities for therapeutic intervention that will have significant implications for a number of pathophysiological conditions. 


\section{ACKNOWLEDGEMENTS}

The authors would like to thank the Wellcome Trust and the Genesis Research Trust for financial support. 


\section{REFERENCES}

Achour, L., Labbe-Jullie, C., Scott, M. G. \& Marullo, S. 2008. An escort for GPCRs: implications for regulation of receptor density at the cell surface.Trends Pharmacol Sci. 29, 528-35.

Allen, J. A., Yu, J. Z., Donati, R. J. \& Rasenick, M. M. 2005. Beta-adrenergic receptor stimulation promotes $G$ alpha $s$ internalization through lipid rafts: a study in living cells.Mol Pharmacol. 67, 1493-504.

Anelli, T. \& Sitia, R. 2008. Protein quality control in the early secretory pathway.EMBO J. 27, 315-27.

Ayala Yanez, R. \& Conn, P. M. 2010. Protein disulfide isomerase chaperone ERP-57 decreases plasma membrane expression of the human $\mathrm{GnRH}$ receptor.Cell Biochem Funct. 28, 66-73.

Azzi, M., Charest, P. G., Angers, S., Rousseau, G., Kohout, T., Bouvier, M. \& Pineyro, G. 2003. Beta-arrestin-mediated activation of MAPK by inverse agonists reveals distinct active conformations for $G$ protein-coupled receptors.Proc Natl Acad Sci U S A. 100, 11406-11.

Bhandari, D., Trejo, J., Benovic, J. L. \& Marchese, A. 2007. Arrestin-2 interacts with the ubiquitin-protein isopeptide ligase atrophin-interacting protein 4 and mediates endosomal sorting of the chemokine receptor CXCR4.J Biol Chem. 282, 36971-9.

Calebiro, D., Nikolaev, V. O., Gagliani, M. C., De Filippis, T., Dees, C., Tacchetti, C., Persani, L. \& Lohse, M. J. 2009. Persistent cAMP-signals triggered by internalized G-protein-coupled receptors.PLoS Biol. 7, e1000172.

Canela, L., Lujan, R., Lluis, C., Burgueno, J., Mallol, J., Canela, E. I., Franco, R. \& Ciruela, F. 2007. The neuronal $\mathrm{Ca}(2+)$-binding protein 2 (NECAB2) interacts with the adenosine $A(2 A)$ receptor and modulates the cell surface expression and function of the receptor.Mol Cell Neurosci. 36, 1-12.

Cao, T. T., Deacon, H. W., Reczek, D., Bretscher, A. \& Von Zastrow, M. 1999. A kinase-regulated PDZ-domain interaction controls endocytic sorting of the beta2-adrenergic receptor.Nature. 401, 286-90.

Chan, L. F., Webb, T. R., Chung, T. T., Meimaridou, E., Cooray, S. N., Guasti, L., Chapple, J. P., Egertova, M., Elphick, M. R., Cheetham, M. E., Metherell, L. A. \& Clark, A. J. 2009. MRAP and MRAP2 are bidirectional regulators of the melanocortin receptor family.Proc Natl Acad Sci U S A. 106, 6146-51.

Chen, Y., Chen, C., Kotsikorou, E., Lynch, D. L., Reggio, P. H. \& Liu-Chen, L. Y. 2009. GEC1-kappa opioid receptor binding involves hydrophobic interactions: GEC1 has chaperone-like effect.J Biol Chem. 284, 1673-85.

Conn, P. M. \& Janovick, J. A. 2009a. Drug development and the cellular quality control system.Trends Pharmacol Sci. 30, 228-33.

Conn, P. M. \& Janovick, J. A. 2009b. Trafficking and quality control of the gonadotropin releasing hormone receptor in health and disease.Mol Cell Endocrinol. 299, 137-45.

Conn, P. M., Ulloa-Aguirre, A., Ito, J. \& Janovick, J. A. 2007. G protein-coupled receptor trafficking in health and disease: lessons learned to prepare for therapeutic mutant rescue in vivo.Pharmacol Rev. 59, 225-50. 
Cooray, S. N., Chan, L., Webb, T. R., Metherell, L. \& Clark, A. J. 2009. Accessory proteins are vital for the functional expression of certain $\mathrm{G}$ protein-coupled receptors.Mol Cell Endocrinol. 300, 17-24.

Dewire, S. M., Ahn, S., Lefkowitz, R. J. \& Shenoy, S. K. 2007. Beta-arrestins and cell signaling.Annu Rev Physiol. 69, 483-510.

Dickinson, R. E., Stewart, A. J., Myers, M., Millar, R. P. \& Duncan, W. C. 2009. Differential expression and functional characterization of luteinizing hormone receptor splice variants in human luteal cells: implications for luteolysis. Endocrinology. 150, 2873-81.

Dong, C., Filipeanu, C. M., Duvernay, M. T. \& Wu, G. 2007. Regulation of G proteincoupled receptor export trafficking.Biochim Biophys Acta. 1768, 853-70.

Drake, M. T., Violin, J. D., Whalen, E. J., Wisler, J. W., Shenoy, S. K. \& Lefkowitz, R. J. 2008. beta-arrestin-biased agonism at the beta2-adrenergic receptor.J Biol Chem. 283, 5669-76.

Dupre, D. J., Baragli, A., Rebois, R. V., Ethier, N. \& Hebert, T. E. 2007. Signalling complexes associated with adenylyl cyclase II are assembled during their biosynthesis. Cell Signal. 19, 481-9.

Dupre, D. J. \& Hebert, T. E. 2006. Biosynthesis and trafficking of seven transmembrane receptor signalling complexes.Cell Signal. 18, 1549-59.

Ellgaard, L. \& Helenius, A. 2003. Quality control in the endoplasmic reticulum.Nat Rev Mol Cell Biol. 4, 181-91.

Ferrandon, S., Feinstein, T. N., Castro, M., Wang, B., Bouley, R., Potts, J. T., Gardella, T. J. \& Vilardaga, J. P. 2009. Sustained cyclic AMP production by parathyroid hormone receptor endocytosis. Nat Chem Biol. 5, 734-42.

Ferrari, S. L., Pierroz, D. D., Glatt, V., Goddard, D. S., Bianchi, E. N., Lin, F. T., Manen, D. \& Bouxsein, M. L. 2005. Bone response to intermittent parathyroid hormone is altered in mice null for \{beta\}-Arrestin2.Endocrinology. 146, 185462.

Filardo, E., Quinn, J., Pang, Y., Graeber, C., Shaw, S., Dong, J. \& Thomas, P. 2007. Activation of the novel estrogen receptor $G$ protein-coupled receptor 30 (GPR30) at the plasma membrane.Endocrinology. 148, 3236-45.

Finch, A. R., Caunt, C. J., Armstrong, S. P. \& Mcardle, C. A. 2009. Agonist-induced internalization and downregulation of gonadotropin-releasing hormone receptors.Am J Physiol Cell Physiol. 297, C591-600.

Frenzel, R., Voigt, C. \& Paschke, R. 2006. The human thyrotropin receptor is predominantly internalized by beta-arrestin 2.Endocrinology. 147, 3114-22.

Gonzalez-Cabrera, P. J., Hla, T. \& Rosen, H. 2007. Mapping pathways downstream of sphingosine 1-phosphate subtype 1 by differential chemical perturbation and proteomics.J Biol Chem. 282, 7254-64.

Guan, R., Feng, X., Wu, X., Zhang, M., Zhang, X., Hebert, T. E. \& Segaloff, D. L. 2009. Bioluminescence resonance energy transfer studies reveal constitutive dimerization of the human lutropin receptor and a lack of correlation between receptor activation and the propensity for dimerization.J Biol Chem. 284, 7483-94.

Guan, R., Wu, X., Feng, X., Zhang, M., Hebert, T. E. \& Segaloff, D. L. 2010. Structural determinants underlying constitutive dimerization of unoccupied human follitropin receptors.Cell Signal. 22, 247-56.

Gurevich, V. V. \& Gurevich, E. V. 2008. How and why do GPCRs dimerize?Trends Pharmacol Sci. 29, 234-40. 
Hanyaloglu, A. C., Mccullagh, E. \& Von Zastrow, M. 2005. Essential role of Hrs in a recycling mechanism mediating functional resensitization of cell signaling.EMBO J. 24, 2265-83.

Hanyaloglu, A. C. \& Zastrow, M. V. 2008. Regulation of GPCRs by Endocytic Membrane Trafficking and Its Potential Implications.Annu Rev Pharmacol Toxicol. 48, 537-568.

Hasdemir, B., Bunnett, N. W. \& Cottrell, G. S. 2007. Hepatocyte growth factorregulated tyrosine kinase substrate (HRS) mediates post-endocytic trafficking of protease-activated receptor 2 and calcitonin receptor-like receptor.J Biol Chem. 282, 29646-57.

Hasdemir, B., Murphy, J. E., Cottrell, G. S. \& Bunnett, N. W. 2009. Endosomal deubiquitinating enzymes control ubiquitination and down-regulation of protease-activated receptor 2.J Biol Chem. 284, 28453-66.

Heitzler, D., Crepieux, P., Poupon, A., Clement, F., Fages, F. \& Reiter, E. 2009. Towards a systems biology approach of $G$ protein-coupled receptor signalling: challenges and expectations.C R Biol. 332, 947-57.

Hislop, J. A., Marley, A. \& Von Zastrow, M. 2004. Role of mammalian VPS proteins in ubiquitination-independent trafficking of $G$ protein-coupled receptors to lysosomes.J Biol Chem. 279, 22522-22531.

Hislop, J. N., Henry, A. G., Marchese, A. \& Von Zastrow, M. 2009. Ubiquitination regulates proteolytic processing of $G$ protein-coupled receptors after their sorting to lysosomes.J Biol Chem. 284, 19361-70.

Huang, S. H., Zhao, L., Sun, Z. P., Li, X. Z., Geng, Z., Zhang, K. D., Chao, M. V. \& Chen, Z. Y. 2009. Essential role of Hrs in endocytic recycling of full-length TrkB receptor but not its isoform TrkB.T1.J Biol Chem. 284, 15126-36.

Innamorati, G., Giannone, F., Guzzi, F., Rovati, G. E., Accomazzo, M. R., Chini, B., Bianchi, E., Schiaffino, M. V., Tridente, G. \& Parenti, M. 2009. Heterotrimeric $G$ proteins demonstrate differential sensitivity to beta-arrestin dependent desensitization.Cell Signal. 21, 1135-42.

Jacob, C., Cottrell, G. S., Gehringer, D., Schmidlin, F., Grady, E. F. \& Bunnett, N. W. 2005. $\mathrm{c}-\mathrm{Cbl}$ mediates ubiquitination, degradation, and down-regulation of human protease-activated receptor 2.J Biol Chem. 280, 16076-87.

Jean-Alphonse, F., Perkovska, S., Frantz, M. C., Durroux, T., Mejean, C., Morin, D., Loison, S., Bonnet, D., Hibert, M., Mouillac, B. \& Mendre, C. 2009. Biased agonist pharmacochaperones of the AVP V2 receptor may treat congenital nephrogenic diabetes insipidus.J Am Soc Nephrol. 20, 2190-203.

Kang-Decker, N., Cao, S., Chatterjee, S., Yao, J., Egan, L. J., Semela, D., Mukhopadhyay, D. \& Shah, V. 2007. Nitric oxide promotes endothelial cell survival signaling through S-nitrosylation and activation of dynamin-2.J Cell Sci. 120, 492-501.

Kenakin, T. 2007. Collateral efficacy in drug discovery: taking advantage of the good (allosteric) nature of 7TM receptors.Trends Pharmacol Sci. 28, 407-15.

Kleijnen, M. F., Shih, A. H., Zhou, P., Kumar, S., Soccio, R. E., Kedersha, N. L., Gill, G. \& Howley, P. M. 2000. The hPLIC proteins may provide a link between the ubiquitination machinery and the proteasome.Mol Cell. 6, 409-19.

Lakshmikanthan, V., Zou, L., Kim, J. I., Michal, A., Nie, Z., Messias, N. C., Benovic, J. L. \& Daaka, Y. 2009. Identification of betaArrestin2 as a corepressor of androgen receptor signaling in prostate cancer.Proc Natl Acad Sci U S A. 106, 9379-84. 
Linderman, J. J. 2009. Modeling of G-protein-coupled receptor signaling pathways.J Biol Chem. 284, 5427-31.

Loconto, J., Papes, F., Chang, E., Stowers, L., Jones, E. P., Takada, T., Kumanovics, A., Fischer Lindahl, K. \& Dulac, C. 2003. Functional expression of murine V2R pheromone receptors involves selective association with the M10 and M1 families of MHC class lb molecules.Cell. 112, 607-18.

Madhra, M., Gay, E., Fraser, H. M. \& Duncan, W. C. 2004. Alternative splicing of the human luteal $\mathrm{LH}$ receptor during luteolysis and maternal recognition of pregnancy.Mol Hum Reprod. 10, 599-603.

Mah, A. L., Perry, G., Smith, M. A. \& Monteiro, M. J. 2000. Identification of ubiquilin, a novel presenilin interactor that increases presenilin protein accumulation.J Cell Biol. 151, 847-62.

Marchese, A., Paing, M. M., Temple, B. R. \& Trejo, J. 2008. G Protein-Coupled Receptor Sorting to Endosomes and Lysosomes.Annu Rev Pharmacol Toxicol. 48, 601-629.

Marchese, A., Raiborg, C., Santini, F., Keen, J. H., Stenmark, H. \& Benovic, J. L. 2003. The E3 ubiquitin ligase AIP4 mediates ubiquitination and sorting of the G protein-coupled receptor CXCR4.Dev Cell. 5, 709-22.

Milligan, G. 2010. The role of dimerisation in the cellular trafficking of G-proteincoupled receptors.Curr Opin Pharmacol. 10, $23-9$.

Minegishi, T., Nakamura, K., Yamashita, S. \& Omori, Y. 2007. The effect of splice variant of the human luteinizing hormone $(\mathrm{LH})$ receptor on the expression of gonadotropin receptor.Mol Cell Endocrinol. 260-262, 117-25.

Moore, C. A., Milano, S. K. \& Benovic, J. L. 2007. Regulation of receptor trafficking by GRKs and arrestins.Annu Rev Physiol. 69, 451-82.

Mosser, V. A., Jones, K. T., Hoffman, K. M., Mccarty, N. A. \& Jackson, D. A. 2008. Differential role of beta-arrestin ubiquitination in agonist-promoted downregulation of M1 vs M2 muscarinic acetylcholine receptors.J Mol Signal. 3, 20.

Mundell, S. J., Luo, J., Benovic, J. L., Conley, P. B. \& Poole, A. W. 2006. Distinct clathrin-coated pits sort different $G$ protein-coupled receptor cargo.Traffic. 7, 1420-31.

N'diaye E, N., Hanyaloglu, A. C., Kajihara, K. K., Puthenveedu, M. A., Wu, P., Von Zastrow, M. \& Brown, E. J. 2008. The Ubiquitin-like Protein PLIC-2 Is a Negative Regulator of G Protein-coupled Receptor Endocytosis.Mol Biol Cell.

N'diaye, E. N., Kajihara, K. K., Hsieh, I., Morisaki, H., Debnath, J. \& Brown, E. J. 2009. PLIC proteins or ubiquilins regulate autophagy-dependent cell survival during nutrient starvation.EMBO Rep. 10, 173-9.

Nakamura, K., Yamashita, S., Omori, Y. \& Minegishi, T. 2004. A splice variant of the human luteinizing hormone $(\mathrm{LH})$ receptor modulates the expression of wildtype human LH receptor.Mol Endocrinol. 18, 1461-70.

Namkung, Y., Dipace, C., Urizar, E., Javitch, J. A. \& Sibley, D. R. 2009. G proteincoupled receptor kinase-2 constitutively regulates D2 dopamine receptor expression and signaling independently of receptor phosphorylation.J Biol Chem. 284, 34103-15.

Nikolaev, V. O., Bunemann, M., Hein, L., Hannawacker, A. \& Lohse, M. J. 2004. Novel single chain cAMP sensors for receptor-induced signal propagation.J Biol Chem. 279, 37215-8.

Oo, M. L., Thangada, S., Wu, M. T., Liu, C. H., Macdonald, T. L., Lynch, K. R., Lin, C. Y. \& Hla, T. 2007. Immunosuppressive and anti-angiogenic sphingosine 1- 
phosphate receptor-1 agonists induce ubiquitinylation and proteasomal degradation of the receptor.J Biol Chem. 282, 9082-9.

Ozawa, K., Whalen, E. J., Nelson, C. D., Mu, Y., Hess, D. T., Lefkowitz, R. J. \& Stamler, J. S. 2008. S-nitrosylation of beta-arrestin regulates beta-adrenergic receptor trafficking.Mol Cell. 31, 395-405.

Parent, A., Laroche, G., Hamelin, E. \& Parent, J. L. 2008. RACK1 regulates the cell surface expression of the $G$ protein-coupled receptor for thromboxane A(2).Traffic. 9, 394-407.

Patial, S., Luo, J., Porter, K. J., Benovic, J. L. \& Parameswaran, N. 2009. G-protein coupled receptor kinases mediate TNFalpha-induced NFkappaB signaling via direct interaction with and phosphorylation of IkappaBalpha.Biochem J.

Pidasheva, S., Grant, M., Canaff, L., Ercan, O., Kumar, U. \& Hendy, G. N. 2006. Calcium-sensing receptor dimerizes in the endoplasmic reticulum: biochemical and biophysical characterization of CASR mutants retained intracellularly.Hum Mol Genet. 15, 2200-9.

Polo, S. \& Di Fiore, P. P. 2006. Endocytosis conducts the cell signaling orchestra.Cell. 124, 897-900.

Puthenveedu, M. A. \& Von Zastrow, M. 2006. Cargo regulates clathrin-coated pit dynamics.Cell. 127, 113-24.

Raiborg, C. \& Stenmark, H. 2009. The ESCRT machinery in endosomal sorting of ubiquitylated membrane proteins.Nature. 458, 445-52.

Regan-Klapisz, E., Sorokina, I., Voortman, J., De Keizer, P., Roovers, R. C., Verheesen, P., Urbe, S., Fallon, L., Fon, E. A., Verkleij, A., Benmerah, A. \& Van Bergen En Henegouwen, P. M. 2005. Ubiquilin recruits Eps15 into ubiquitin-rich cytoplasmic aggregates via a UIM-UBL interaction.J Cell Sci. $118,4437-50$.

Reiter, E. \& Lefkowitz, R. J. 2006. GRKs and beta-arrestins: roles in receptor silencing, trafficking and signaling. Trends Endocrinol Metab. 17, 159-65.

Revankar, C. M., Cimino, D. F., Sklar, L. A., Arterburn, J. B. \& Prossnitz, E. R. 2005. A transmembrane intracellular estrogen receptor mediates rapid cell signaling.Science. 307, 1625-30.

Reyes-lbarra, A. P., Garcia-Regalado, A., Ramirez-Rangel, I., Esparza-Silva, A. L., Valadez-Sanchez, M., Vazquez-Prado, J. \& Reyes-Cruz, G. 2007. Calciumsensing receptor endocytosis links extracellular calcium signaling to parathyroid hormone-related peptide secretion via a Rab11a-dependent and AMSH-sensitive mechanism.Mol Endocrinol. 21, 1394-407.

Ricks, T. K. \& Trejo, J. 2009. Phosphorylation of protease-activated receptor-2 differentially regulates desensitization and internalization.J Biol Chem. 284, 34444-57.

Rivas, M., Mellstrom, B., Torres, B., Cali, G., Ferrara, A. M., Terracciano, D., Zannini, M., Morreale De Escobar, G. \& Naranjo, J. R. 2009. The DREAM protein is associated with thyroid enlargement and nodular development.Mol Endocrinol. 23, 862-70.

Robben, J. H. \& Deen, P. M. 2007. Pharmacological chaperones in nephrogenic diabetes insipidus: possibilities for clinical application.BioDrugs. 21, 157-66.

Robben, J. H., Kortenoeven, M. L., Sze, M., Yae, C., Milligan, G., Oorschot, V. M., Klumperman, J., Knoers, N. V. \& Deen, P. M. 2009. Intracellular activation of vasopressin V2 receptor mutants in nephrogenic diabetes insipidus by nonpeptide agonists.Proc Natl Acad Sci U S A. 106, 12195-200. 
Seachrist, J. L. \& Ferguson, S. S. 2003. Regulation of G protein-coupled receptor endocytosis and trafficking by Rab GTPases.Life Sci. 74, 225-35.

Sexton, P. M., Morfis, M., Tilakaratne, N., Hay, D. L., Udawela, M., Christopoulos, G. \& Christopoulos, A. 2006. Complexing receptor pharmacology: modulation of family B G protein-coupled receptor function by RAMPs.Ann N Y Acad Sci. 1070, 90-104.

Shenoy, S. K. 2007. Seven-transmembrane receptors and ubiquitination.Circ Res. $100,1142-54$.

Shenoy, S. K., Barak, L. S., Xiao, K., Ahn, S., Berthouze, M., Shukla, A. K., Luttrell, L. M. \& Lefkowitz, R. J. 2007. Ubiquitination of beta-arrestin links seventransmembrane receptor endocytosis and ERK activation.J Biol Chem. 282, 29549-62.

Shenoy, S. K., Xiao, K., Venkataramanan, V., Snyder, P. M., Freedman, N. J. \& Weissman, A. M. 2008. Nedd4 mediates agonist-dependent ubiquitination, lysosomal targeting, and degradation of the beta2-adrenergic receptor.J Biol Chem. 283, 22166-76.

Shukla, A. K., Violin, J. D., Whalen, E. J., Gesty-Palmer, D., Shenoy, S. K. \& Lefkowitz, R. J. 2008. Distinct conformational changes in beta-arrestin report biased agonism at seven-transmembrane receptors.Proc Natl Acad Sci U S A. 105, 9988-93.

Slessareva, J. E., Routt, S. M., Temple, B., Bankaitis, V. A. \& Dohlman, H. G. 2006. Activation of the phosphatidylinositol 3-kinase Vps34 by a $\mathrm{G}$ protein alpha subunit at the endosome.Cell. 126, 191-203.

Sorkin, A. \& Von Zastrow, M. 2009. Endocytosis and signalling: intertwining molecular networks. Nat Rev Mol Cell Biol. 10, 609-22.

Tan, C. M., Brady, A. E., Nickols, H. H., Wang, Q. \& Limbird, L. E. 2004. Membrane trafficking of $G$ protein-coupled receptors.Annu Rev Pharmacol Toxicol. 44, 559-609.

Tanowitz, M. \& Von Zastrow, M. 2002. Ubiquitination-independent trafficking of G protein-coupled receptors to lysosomes.J Biol Chem. 277, 50219-22.

Tao, J. \& Malbon, C. C. 2008. G-protein-coupled receptor-associated A-kinase anchoring proteins AKAP5 and AKAP12: differential signaling to MAPK and GPCR recycling.J Mol Signal. 3, 19.

Tao, J., Wang, H. Y. \& Malbon, C. C. 2003. Protein kinase A regulates AKAP250 (gravin) scaffold binding to the beta2-adrenergic receptor.EMBO J. 22, 641929.

Tao, J., Wang, H. Y. \& Malbon, C. C. 2007. Src docks to A-kinase anchoring protein gravin, regulating beta2-adrenergic receptor resensitization and recycling.J Biol Chem. 282, 6597-608.

Terrillon, S., Durroux, T., Mouillac, B., Breit, A., Ayoub, M. A., Taulan, M., Jockers, R., Barberis, C. \& Bouvier, M. 2003. Oxytocin and vasopressin V1a and V2 receptors form constitutive homo- and heterodimers during biosynthesis.Mol Endocrinol. 17, 677-91.

Vines, C. M., Revankar, C. M., Maestas, D. C., Larusch, L. L., Cimino, D. F., Kohout, T. A., Lefkowitz, R. J. \& Prossnitz, E. R. 2003. N-formyl peptide receptors internalize but do not recycle in the absence of arrestins.J Biol Chem. 278, 41581-4.

Violin, J. D. \& Lefkowitz, R. J. 2007. Beta-arrestin-biased ligands at seventransmembrane receptors.Trends Pharmacol Sci. 28, 416-22. 
Von Zastrow, M., Svingos, A., Haberstock-Debic, H. \& Evans, C. 2003. Regulated endocytosis of opioid receptors: cellular mechanisms and proposed roles in physiological adaptation to opiate drugs.Curr Opin Neurobiol. 13, 348-53.

Wagener, B. M., Marjon, N. A., Revankar, C. M. \& Prossnitz, E. R. 2009. Adaptor protein-2 interaction with arrestin regulates GPCR recycling and apoptosis. Traffic. 10, 1286-300.

Walters, K. J., Kleijnen, M. F., Goh, A. M., Wagner, G. \& Howley, P. M. 2002. Structural studies of the interaction between ubiquitin family proteins and proteasome subunit S5a.Biochemistry. 41, 1767-77.

Wang, B., Bisello, A., Yang, Y., Romero, G. G. \& Friedman, P. A. 2007. NHERF1 regulates parathyroid hormone receptor membrane retention without affecting recycling.J Biol Chem. 282, 36214-22.

Wang, B., Yang, Y., Abou-Samra, A. B. \& Friedman, P. A. 2009. NHERF1 regulates parathyroid hormone receptor desensitization: interference with beta-arrestin binding.Mol Pharmacol. 75, 1189-97.

Wang, F., Chen, X., Zhang, X. \& Ma, L. 2008. Phosphorylation state of mu-opioid receptor determines the alternative recycling of receptor via Rab4 or Rab11 pathway.Mol Endocrinol. 22, 1881-92.

Wang, G., Moniri, N. H., Ozawa, K., Stamler, J. S. \& Daaka, Y. 2006. Nitric oxide regulates endocytosis by S-nitrosylation of dynamin.Proc Natl Acad Sci U S A. 103, 1295-300.

Webb, T. R. \& Clark, A. J. 2009. Minireview: The Melanocortin 2 Receptor Accessory Proteins.Mol Endocrinol.

Weinman, E. J., Hall, R. A., Friedman, P. A., Liu-Chen, L. Y. \& Shenolikar, S. 2006. The association of NHERF adaptor proteins with $\mathrm{g}$ protein-coupled receptors and receptor tyrosine kinases.Annu Rev Physiol. 68, 491-505.

Whalen, E. J., Foster, M. W., Matsumoto, A., Ozawa, K., Violin, J. D., Que, L. G., Nelson, C. D., Benhar, M., Keys, J. R., Rockman, H. A., Koch, W. J., Daaka, Y., Lefkowitz, R. J. \& Stamler, J. S. 2007. Regulation of beta-adrenergic receptor signaling by S-nitrosylation of G-protein-coupled receptor kinase 2.Cell. 129, 511-22.

Wheeler, D., Sneddon, W. B., Wang, B., Friedman, P. A. \& Romero, G. 2007. NHERF-1 and the cytoskeleton regulate the traffic and membrane dynamics of G protein-coupled receptors.J Biol Chem. 282, 25076-87.

Williams, D. B. 2006. Beyond lectins: the calnexin/calreticulin chaperone system of the endoplasmic reticulum.J Cell Sci. 119, 615-23.

Wu, A. L., Wang, J., Zheleznyak, A. \& Brown, E. J. 1999. Ubiquitin-related proteins regulate interaction of vimentin intermediate filaments with the plasma membrane.Mol Cell. 4, 619-25.

Yamashita, S., Nakamura, K., Omori, Y., Tsunekawa, K., Murakami, M. \& Minegishi, T. 2005. Association of human follitropin (FSH) receptor with splicing variant of human lutropin/choriogonadotropin receptor negatively controls the expression of human FSH receptor.Mol Endocrinol. 19, 2099-111.

Yudowski, G. A., Puthenveedu, M. A., Henry, A. G. \& Von Zastrow, M. 2009. Cargomediated regulation of a rapid Rab4-dependent recycling pathway.Mol Biol Cell. 20, 2774-84.

Yudowski, G. A., Puthenveedu, M. A. \& Von Zastrow, M. 2006. Distinct modes of regulated receptor insertion to the somatodendritic plasma membrane.Nat Neurosci. 9, 622-7. 
Zarinan, T., Perez-Solis, M. A., Maya-Nunez, G., Casas-Gonzalez, P., Conn, P. M., Dias, J. A. \& Ulloa-Aguirre, A. 2010. Dominant negative effects of human follicle-stimulating hormone receptor expression-deficient mutants on wild-type receptor cell surface expression. Rescue of oligomerization-dependent defective receptor expression by using cognate decoys.Mol Cell Endocrinol. $321,112-22$. 


\section{FIGURE LEGENDS}

Figure 1. The trafficking life cycle of GPCRs. Following synthesis, GPCRs are transported through the endoplasmic reticulum (ER) and Golgi compartments where they engage in a number of protein interactions that regulate their maturation and control their surface targeting (see text). Once at the membrane the receptor is able to bind its ligand, activating heterotrimeric G-protein signaling. Following activation, GPCRs are rapidly phosphorylated by kinases such as GRKs, or second messenger kinases such as PKA or PKC. $\beta$-arrestin (Arr) is then rapidly recruited from the cytosol to the activated, phosphorylated GPCR, which uncouples the receptor from its G-protein and targets receptors to clathrin-coated pits (CCPs) for its internalization, resulting in rapid desensitization of G-protein signaling. However, the arrestin-bound GPCR can also lead to activation of non-G-protein mediated signaling. Internalized receptor in early endosomes can then be trafficked to various post-endocytic compartments. Trafficking to Rab7 late endosomes can lead to involution of receptors to form multivesicular bodies (MVBs) where subsequent fusion with lysosomes leads to receptor degradation and complete signal termination. GPCRs can also traffic to rapid (Rab4) or slow (Rab11) recycling compartments, a critical trafficking step for functional signal resensitization at the plasma membrane. $\mathrm{CCP}=$ clathrin-coated pit; $\mathrm{EE}=$ early endosome; $\mathrm{RE}=$ recycling endosome; LE/MVB=late endosome/multivesicular body; LY=lysosome. Orange 'halo' at GPCR denotes heterotrimeric $\mathrm{G}$ protein-signals, green halo denotes, $\beta$-arrestin-mediated, non-G protein signaling.

Figure 2. Membrane trafficking of GPCRs provides novel compartments for Gprotein signaling. Heterotrimeric G-protein signaling is normally associated as a plasma membrane signaling event (Conventional model). However, recent studies have shown evidence for GPCRs to complex and signal with their cognate G-proteins at intracellular sites (Non-conventional model). GPCR signaling from the ER/Golgi has been observed by utilizing membrane permeable agonists that activate GPCRs without affecting maturation and cell surface expression (see text for details). Certain GPCRs also have been shown to co-localize with their G-proteins at the endosomes and exhibit a sustained G-protein signaling profile. This sustained signaling required receptor internalization (see text). Orange halo denotes G-protein signal from receptor.

Figure 3. Complex trafficking pathways acutely regulate spatio-temporal dynamics of GPCR signaling. Membrane trafficking is regulated by a number of factors that involve both positive and negative mechanistic regulation of multiple trafficking steps. This cartoon illustrates just a few of the pathways and molecules discussed in the review (black dotted arrows), focusing on events following receptor activation at the cell surface. Novel mediators of agonist-induced internalization depicted include S-nitrosylation by eNOS of GRK and $\beta$-arrestin, and negative regulation of GPCR/ $\beta$-arrestin clustering in CCPs by PLIC-2. Targeting of GPCRs to the lysosome involves a cycle of ubiquitination/deubiquitnation of either receptor, or as yet, unknown protein targets at distinct points in the pathway. Sorting of GPCRs to the recycling pathway requires C-tail sequences e.g. PDZ ligands and Hrs for rapid recycling. However, the identities of the recycling proteins are not clear for all GPCRs. PDZ domain interactions may also facilitate association with scaffolding complexes such as the AKAPs that could provide spatio-temporal control to trafficking and signaling. Both PKA phosphorylation of receptor and Rab4 mediate 
the rate of very rapid receptor recycling. $C C P=$ clathrin-coated pit; $E E=e a r l y$ endosome; RE=recycling endosome; LE/MVB=late endosome/multivesicular body; $\mathrm{LY}=$ lysosome. 


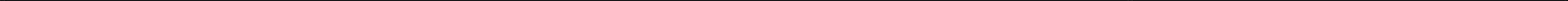




\section{Figure 3}

ACCEPTED MANUSCRIP

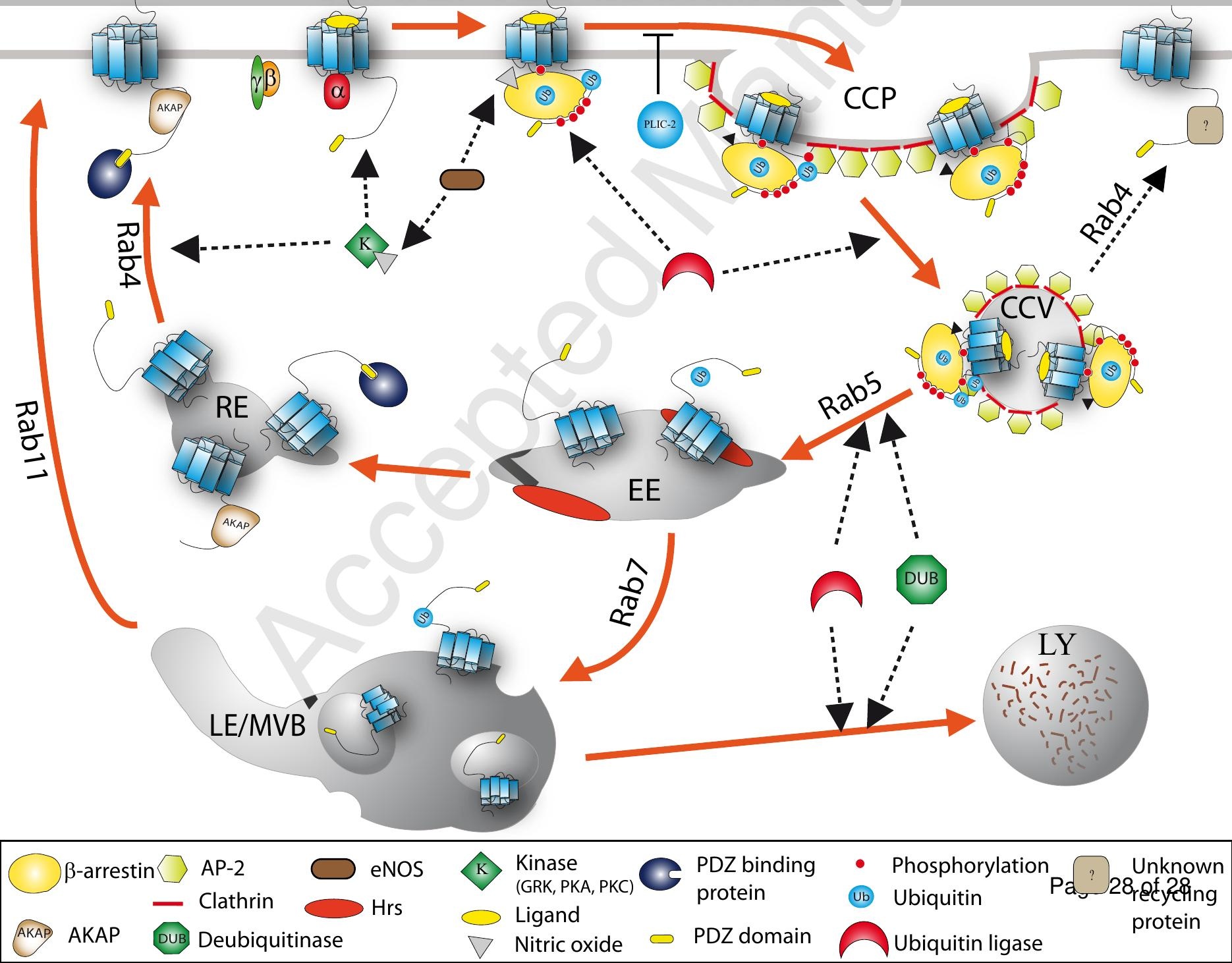

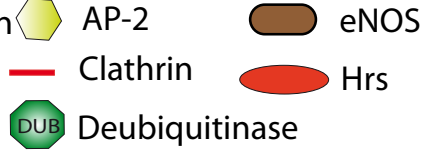

$\nabla$ Nitric oxide 